\section{Review Article}

J Exp Clin Med

2021; 38(S2): 136-142

doi: 10.52142/omujecm.38.si.dent.10

\title{
Direct digitalization devices in today's dental practice: Intra oral scanners
}

\author{
Çağrı URAL ${ }^{1, *}$, Necati KALELi \\ ${ }^{1}$ Department of Prosthodontics, Faculty of Dentistry, Ondokuz Mayis University, Samsun, Turkey \\ ${ }^{2}$ Department of Dentistry Services, Vocational School of Health Services, Ondokuz Mayis University, Samsun, Turkey
}

\begin{abstract}
\begin{tabular}{ccccc}
\hline Received: 24.05 .2020 & $\bullet$ & Accepted/Published Online: 07.12.2020 & Final Version: 19.05 .2021 \\
\hline
\end{tabular}
Abstract

Rapidly developing technologies and new changes in modern dentistry have led to more effective solutions to be used in our clinical practice. The digital workflow includes some steps, such as data acquisition, digitalization, designing, and subsequently manufacturing by using digital devices. In this process, acquiring the images from patients' mouth, which is named computer-aided impression (CAI), is the first step of the digital workflow and named as digitalization. The need to skip many time-consuming intermediate steps and reduce the possibility of fabrication errors has made the digital workflow a popular choice for dentists and dental technicians. The popularity of intraoral scanners has increased rapidly since the 1980 s. With the development of camera systems and software engineering, many companies have presented many different IOS devices, which are based on different software systems. This situation causes dentists to get confused due to the formation of a large data cluster. IOS devices are used to capture the digital data and they are an effective alternative to conventional impressions in many ways, such as increased patient comfort, time efficiency, hygiene, predictability, and precise results. Clinicians should have enough technical information about the IOS they use to obtain optimal results in fabricated restorations. The aim of this review is to evaluate the scanning technologies of intraoral scanners, their advantages, and disadvantages in clinical practice, scanning strategies, accuracy of scanning processes, and software protocols.
\end{abstract}

Keywords: CAD-CAM, digital dentistry, digital workflow, intraoral scanners

\section{Introduction}

The main goal of the dentistry is to provide an optimal treatment modality to patients. The modern dentistry still looks for new opportunities regarding with new challenges. The conventional workflow in restorative dentistry generally involves an impression process as the first step to obtain the data, and a model fabrication process as the subsequent step. Although this workflow has some disadvantages, such as dimensional stability and accuracy problems, conventional workflow is still used in routine dental practice. Nevertheless, rapidly developing technologies and new changes in modern dentistry have led to more effective solutions to be used in our clinical practice (Moörmann, 2006; Miyazaki et al., 2009; Persson et al., 2009; Chiu et al., 2020). The workflow, which includes the data acquisition, digitalization, designing, and subsequently manufacturing by using digital fabrication devices is called complete digital workflow, and this workflow is about to be used in routine clinical practice. Complete digital workflow is also defined as computer-aided design and computer-aided manufacturing (CAD-CAM) process, and this technology has provided a highly effective, predictable, and accurate workflow for our modern dentistry since it was introduced in 1980's. (Moörmann, 2006; Miyazaki et al., 2009; Persson et al., 2009; Chiu et al., 2020).
In this process, acquiring the images from restoration site, which is named computer-aided impression (CAI), is the first step for the digital workflow and named as digitalization. Intraoral scanner (IOS) devices used to capture the digital data, and they are an effective alternative to conventional impressions in terms of many ways, such as increased patient comfort, time efficiency, hygiene, predictable and precise results. Other advantages of intraoral scanners include realtime visualization, and objective and simple communication between patients and technicians. The use of IOSs to acquire digital images of restoration area has become a common modality for fixed prosthodontic treatments (Giachetti et al., 2020).

In the available literature, there are many studies comparing digital impression methods with conventional impression techniques as an alternative workflow. Since the digital impression systems offer improved reliability and reproducibility, their acceptance and popularity have increased (Punj et al., 2017; Chiu et al., 2020). With the rapid development of this technology, the number of dentists, who use digital technology in their routine clinical practice, has increased. 
The IOS devices mainly consist of three components: portable digital camera (hardware), computer, and software. The main goal is to obtain the surface properties of related area as $3 \mathrm{D}$ and precisely. Subsequently, the obtained data are transferred to a design software and the design process of the restoration begins. Although these devices generally use standard tessellation language (.stl) file format to transfer the data to the design softwares, some other file formats have been developed to obtain color and texture of dental tissues, such as polygon file format (.ply). These file formats are also used in other fields of industry.

The basic philosophy of the IOSs is transferring the surfaces into a point cloud. Subsequently, this point cloud is transferred into triangles connected to each other by the help of software (Richert et al., 2017). Each triangle can be defined as three points on surface. Regardless of camera type, all IOS systems require a light projection, which is recorded as images or capturing videos and compiled by specific software after recognition of POI (Points of interest). To detect these points, first two coordinates ( $\mathrm{x}$ and $\mathrm{y}$ ) of each point are calculated, and the final coordinate is calculated according to distance from the camera to the object (Ireland et al., 2008; Geng, 2011; Richert et al., 2017).

\section{Scanning technologies of intraoral scanners}

The technologies, which are used to capture the digital images of restoration areas, can be divided into five main categories:

\section{Light Projection and capture}

Passive and active techniques can be used. The active and passive classification mainly depends on the light, which is used by the IOS to detect surface properties. If the camera uses a light source, it is called as active, whereas if the IOS use only ambient lightening, it is called as passive (Fig. 1). White, red, or blue lights can be used. In active technologies, a luminous point of light is reflected onto the object and the distance is calculated by triangulation process (Taneva et al., 2015; Richert et al., 2017).

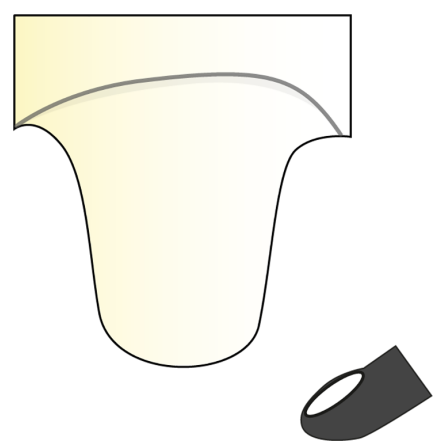

Fig. 1. Scanning tip that using light for image capturing

\section{Triangulation}

This philosophy mainly depends on the calculation of a point, which is a part of triangle that can be calculated when the other two points and angles are known. These two points can be detected by a double camera system, or a single camera system that uses a prism or other technologies (Fig. 2).

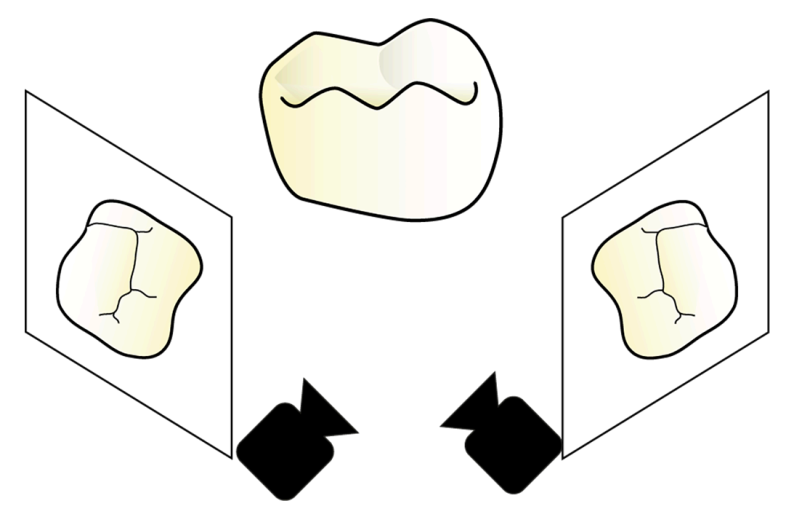

Fig. 2. Determining the distance of the object by using triangulation technique

\section{Confocal technologies}

Confocal technology works with the acquisition of focused and defocused images from selected teeth surfaces (Fig. 3). A successful digital impression and acquisition can be obtained by taken images with different focuses and aperture values from different angles of scanned region. This technology requires larger optics (Giménez et al., 2015; Richert et al., 2017).

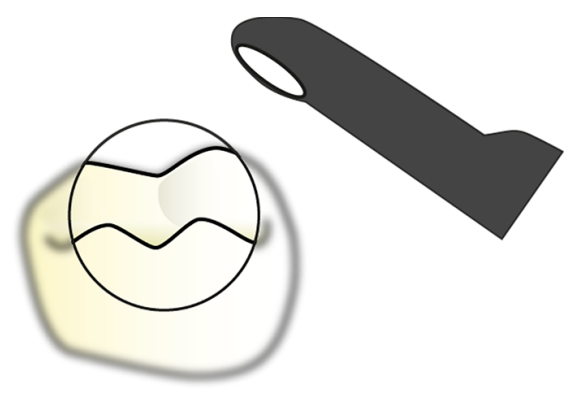

Fig. 3. Distance to the object is determined by the focal distance

\section{AWS (Active Wave Front Sampling)}

AWS is a surface imaging technique that requires a camera and an off-axis diaphragm module (Fig. 4). The module moves in a circular path around the optical axis and produces a POI rotation. The information of distance and depth are then derived from the model produced by each point and calculated (Logozzo et al., 2014; Richert et al., 2017).

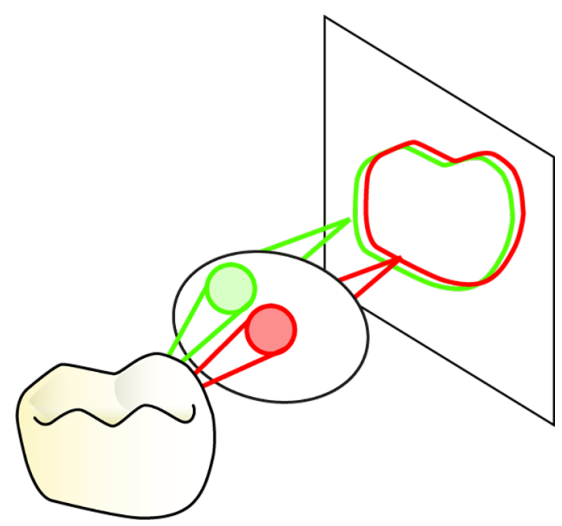

Fig. 4. AWS requires a circular path around the optical axis and produces a rotation of interest points 


\section{Stereophotogrammetry}

This system can be described as a technology with high level of accuracy, which allows to determine the spatial positions of different objects. The accuracy is ensured by recording multiple photographs from different angles and constant distance. This technology was frequently used in engineering and fabrication process, architecture, and topography mapping. It has been used in dentistry since 1990s. Stereophotogrammetry may be particularly important for implant-supported restorations because frameworks, which have an error of only $10-\mu \mathrm{m}$, can be fabricated by using the obtained spatial positions of the implants. Moreover, the passive fit of the restoration can be achieved more accurately (Fig. 5).

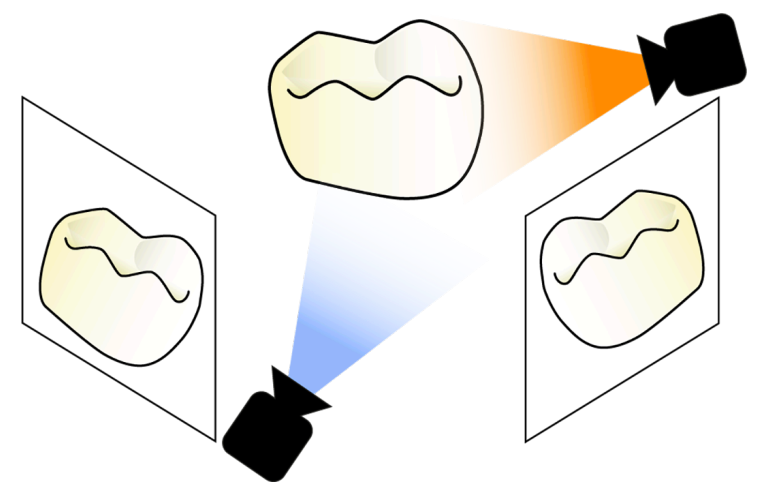

Fig. 5. Stereophotogrammetry is a technology that generates files by algorithm analyzing numerous pictures

One of the most important advantages of this technology is improved patient comfort. Another important advantage is that the operator does not need to take an impression both by conventional and digital. Nevertheless, one disadvantage of this system is that this technology is restricted to large implant cases, as it is not possible to obtain digital data for a single implant case. Also, this technology cannot be used in digitalization of tooth-borne restorations or soft tissues. To acquire the data of soft tissues in implant cases, an additional conventional or digital impression is taken and combined the data acquired by stereophotogrammetry system (Tamimi and Hirayama, 2019).

\section{IOS usage in dental clinics}

\section{What are the advantages and disadvantages?}

Recent studies have indicated that digital impression techniques are much faster and comfortable for both patients and clinicians (Patzelt et al., 2014a; Gjelvold et al., 2016; Richert et al., 2017). In conventional impressions, some problems may occur, such as gag reflex, and some patients cannot tolerate this situation. In these cases, replacing the conventional impressions with digital ones is a considerably important advantage. However, many studies reported that digital impressions are more time efficient when compared with conventional impressions due to absence of long working times. Although most of the research reported that full arch scan duration with an IOS device is indicated under $3 \mathrm{~min}$. (Grünheid et al., 2014; Goracci et al., 2016; Mangano et al.,
2017) according to learning curve and experience of clinician, this duration can be up to 3-5 min after completing the scanning process. It is possible to send the stl file of working digital model via by e-mail to the dental laboratory, and hence save money and time.

Another advantage is simplified procedure in complex cases, such as implant-supported restorations and cases with undercuts. The digital impression is simpler and more comparable when compared with the conventional impression in such cases (Lee and Gallucci, 2013; Joda and Braegger, 2015; Mangano et al., 2017). Moreover, if the clinician is not satisfied with the result, renewal of the impression is easier and more economical in the digital workflow. The communication is another important issue. The digital technology ensures that the clinicians make this communication more objectively and with real time. In fact, lab technicians can check the impression immediately after the scanning procedure and clinicians can discuss on every issue. Also, digital impressions are a powerful tool for marketing and communication in terms of patient communication.

Consequently, the advantages can be classified as follows: less patient discomfort, time efficient, simplified clinical procedures, absence of plaster casts, better and objective communication with dental technicians, better communication with patients. Nevertheless, IOS technologies have some disadvantages, such as detecting the deep marginal lines above the soft tissues, the need for to reach learning curve, and managing cost (Ting-Shu and Jian, 2015; Zimmermann et al., 2015; Mangano et al., 2017).

\section{Which technology?}

Lee and Gallucci have reported that confocal technology is better for short, prepared teeth, and implant restorations that are scanned by unexperienced clinicians (Lee and Gallucci, 2013). On the other hand, even if some studies have indicated that confocal and AWS technologies have been frequently preferred for digital impressions, this does not indicate that which technology is better because the accuracy mostly depends on the software and employed technology (Richert et al., 2017). A whole series of elements (necessity of opacization with powder, scanning speed, tip size, ability to detect incolour impressions) differentiate IOSs in terms of their clinical use and accuracy (Mangano et al., 2017).

\section{Learning curve}

Previous related studies exhibited that the clinicians using IOSs would need time and education to develop their skills and complete the digital impression rapidly with high accuracy (Ender and Mehl, 2015; Lim et al., 2018). The scanning time differs from 4 to 15 minutes and this is also related with the software technology employed and scanning strategy (Richert et al., 2017). In the literature, there are many studies, which evaluated the effects of repeated practice and learning curve when a new technology or technique introduced. The developing skill on a new device also increases the treatment 
Table 1. Overview of intraoral scanners systems available on the market (Zimmerman et al., 2015)

\begin{tabular}{|c|c|c|c|c|c|c|c|c|c|c|}
\hline & $\begin{array}{l}\text { 3M Espe True } \\
\text { Definition }\end{array}$ & 3Shape Trios 3 & $\begin{array}{c}\text { Align } \\
\text { Technology } \\
\text { Itero } \\
\text { Element }\end{array}$ & $\begin{array}{l}\text { Carestream } \\
\text { CS3500 }\end{array}$ & $\begin{array}{l}\text { Dental } \\
\text { Wings } \\
\text { Dwio }\end{array}$ & Gc Aadva & Kavo Lythos & $\begin{array}{c}\text { Planmeca Plan } \\
\text { Scan }\end{array}$ & $\begin{array}{c}\text { Sirona } \\
\text { Cerec } \\
\text { Omnicam }\end{array}$ & Medit i500 \\
\hline Powder & Yes & Yes & No & No & No & No & No & No & No & No \\
\hline Color & No & Yes & Yes & Yes & Yes & No & Yes & Yes & Yes & Yes \\
\hline $\begin{array}{l}\text { Scanner Size } \\
(\mathrm{LxWxH})\end{array}$ & $\begin{array}{l}254 \times 16 \times 14 \\
\mathrm{~mm}\end{array}$ & No details given & $\begin{array}{l}\text { No details } \\
\text { given }\end{array}$ & $\begin{array}{l}245 \times 62 \times 37 \\
\mathrm{~mm}\end{array}$ & $\begin{array}{l}\text { No details } \\
\text { given }\end{array}$ & $\begin{array}{l}160 \times 260 \times 160 \\
\mathrm{~mm}\end{array}$ & $\begin{array}{l}\text { No details } \\
\text { given }\end{array}$ & $\begin{array}{l}\text { No details } \\
\text { given }\end{array}$ & $\begin{array}{l}228 \times 16 \times 16 \\
\mathrm{~mm}\end{array}$ & $\begin{array}{l}19 \times 15.2 \mathrm{~mm} \\
(\mathrm{~W} \times \mathrm{H})\end{array}$ \\
\hline $\begin{array}{l}\text { Data Capture } \\
\text { Mode }\end{array}$ & $\begin{array}{l}\text { Video } \\
\text { Squence }\end{array}$ & Video Sequence & $\begin{array}{l}\text { Video } \\
\text { Sequence }\end{array}$ & $\begin{array}{l}\text { İndividual } \\
\text { images }\end{array}$ & $\begin{array}{l}\text { Video } \\
\text { Sequence }\end{array}$ & $\begin{array}{l}\text { Video } \\
\text { Sequence }\end{array}$ & $\begin{array}{l}\text { Video } \\
\text { Sequence }\end{array}$ & $\begin{array}{l}\text { Video } \\
\text { Sequence }\end{array}$ & $\begin{array}{l}\text { Video } \\
\text { Sequence }\end{array}$ & $\begin{array}{l}\text { Video } \\
\text { Sequence }\end{array}$ \\
\hline $\begin{array}{l}\text { Data Capture } \\
\text { Principle }\end{array}$ & $\begin{array}{l}\text { Wave front } \\
\text { Sampling }\end{array}$ & $\begin{array}{l}\text { Confocal laser } \\
\text { technology }\end{array}$ & $\begin{array}{l}\text { Confocal } \\
\text { microscopy }\end{array}$ & Triangulation & $\begin{array}{l}\text { Multiscan } \\
\text { imaging }\end{array}$ & $\begin{array}{l}\text { Confocal } \\
\text { microscopy }\end{array}$ & Triangulation & Triangulation & Triangulation & Triangulation \\
\hline Chairside & Established & Established & $\begin{array}{l}\text { Not } \\
\text { everywhere }\end{array}$ & Established & $\begin{array}{l}\text { Not } \\
\text { established }\end{array}$ & $\begin{array}{l}\text { Not } \\
\text { established }\end{array}$ & Established & Established & Established & $\begin{array}{l}\text { Not } \\
\text { established }\end{array}$ \\
\hline Labside & Established & Established & Established & Established & Established & Established & Established & Established & Established & $\begin{array}{l}\text { Not } \\
\text { established }\end{array}$ \\
\hline Implantology & Established & Established & Established & $\begin{array}{l}\text { Not } \\
\text { established }\end{array}$ & $\begin{array}{l}\text { Partly } \\
\text { established }\end{array}$ & $\begin{array}{l}\text { Not } \\
\text { established }\end{array}$ & $\begin{array}{l}\text { Not } \\
\text { established }\end{array}$ & $\begin{array}{l}\text { Not } \\
\text { established }\end{array}$ & Established & Established \\
\hline Orthdontics & Established & Established & Established & $\begin{array}{l}\text { Partly } \\
\text { established }\end{array}$ & $\begin{array}{l}\text { Partly } \\
\text { established }\end{array}$ & $\begin{array}{l}\text { Not } \\
\text { established }\end{array}$ & $\begin{array}{l}\text { Not } \\
\text { established }\end{array}$ & $\begin{array}{l}\text { Not } \\
\text { established }\end{array}$ & Established & $\begin{array}{l}\text { Partly } \\
\text { established }\end{array}$ \\
\hline
\end{tabular}

quality and decreases the treatment time. As parallel with these statements, Lim et al. (2018) reported that repeated experience, clinical experience, and the scanned region all affected the trueness of the scanned images in the single-image-based systems.

\section{Scanning strategies (scanning path)}

Scan path or strategies can be defined as specific movements of IOS during the scanning procedure to increase the accuracy of digital impressions. Both invitro and in vivo studies exhibited that the accuracy of digital impressions is affected by the scanning strategies (Zimmermann et al., 2015; Müller et al., 2016).

The scanned object should be placed in the middle of an acquisition area to identify the most appropriate sphere around the object. Practitioners must also control the fluid movement, and the camera should be hold between 5 and $30 \mathrm{~mm}$ of the scanned surface depending on the focal distance of scanner (Logozzo et al., 2014; Richert et al., 2017). This handling procedure is not quite easy, especially during the transition between anterior and posterior sites. Different strategies were presented according to different technologies of IOS devices. The most used and advised strategy is linear movement of the camera over all the occlusal surfaces followed by scanning of buccal and palatal surfaces. Another strategy consists of making an "S" movement on vestibular, occlusal, and lingual surfaces.

The linear movement strategy limits the 3D distortion by finishing the capture at the initial position. However, this strategy has one limitation; this type of movement may cause imprecise scans especially on interproximal areas (Müller et al., 2016; Richert et al., 2017). The most difficult areas of scanning are interproximal areas, high curvatures of central incisive and axis around canines, and steep downward slopes, such as lingual area of mandibular incisors. The clinicians must adapt their own clinical protocols in these areas to overcome the imprecise scanning problems. In this situation, the IOS tracking, and software of the technology become more important.

\section{Scanning flow and software}

During the intraoral scanning, some problems may occur, such as tracking lost or stopped capturing. This situation is an unexpected result for the clinicians, and it may be uncomfortable for both clinicians and patients. The movement can be visualized too slow, too fast, or too jerky. In these types of situations, the followed scanning strategy should be start from the beginning. First, the clinician should scan easy areas, such as occlusal surfaces of posterior teeth, so the IOS can continue to capture again and go on scanning process. Currently, manufacturers develop different strategies and software algorithms to continue scanning when tracking is lost, and these algorithms are mainly based on recognizing the saved geometry of the object (Richert et al., 2017). For this reason, clinicians have to give enough information for stitching the first and last scan data. The second scan allows matching the previous POI, and software complete the missing part of scanned area (Mao et al., 2014).

\section{Accuracy of digital impressions}

In the literature, the accuracy of digital impression is determined by two measurements, one is trueness and the other one is precision. Trueness refers to the closeness of consistency between the arithmetic mean of a large number of test results and the true or accepted reference value (Richert et al., 2017). Precision refers to the closeness of consistency between test results. The method of measurement contributes to the variability of trueness and precision reported for the IOS, as this depends on aspects, such as the operator, equipment and calibration, the time elapsed between measurements, and the environment (temperature, humidity, etc.). Precision describes how repeated measures are close to each other. Therefore, a scanner with high precision correlates to a more repeatable and consistent scan (Renne et al., 2017). Trueness describes how far the measurement deviates from the measured objects (Ender and Mehl, 2013; Renne et al., 2017). Therefore, a scanner with high trueness indicates that it can deliver close results to the actual dimensions of the scanned object. Ultimately, the accuracy can be defined as the summary of trueness and precision. Ideally, an IOS device should have high 
trueness values, and the virtual model, which is acquired from the digital impression should match up with the scanned area.

Currently, the scientific literature considers that the accuracy of optical impression systems is considerable in case of single tooth restorations and partial fixed dentures up to 4-5 units. Today, it can be reported that the trueness of optical impressions in case of short span areas are comparable with the conventional impression techniques (Mangano et al., 2017). However, optical impressions cannot show the same accuracy values in complete edentulous or long span areas (more than 5 units) in both tooth-borne and implant supported restorations (Mangano et al., 2017). In complete edentulous patients, the optical impression acquired by using confocal, AWS, and triangulation languages, the success of digital impressions is less accurate in terms of deformation of acquired images when compared with conventional impressions. Most of the related literature reported positive results in single implant-supported restorations. However, the accuracy of digital impressions can decrease when the inter-implant distance increased. Also, the accuracy of digital impressions can be affected by the learning curve, as well (Logozzo et al., 2014; Richert et al., 2017).

Ender and Mehl (2013) found that conventional impressions were significantly more accurate than digital impressions in complete arch treatments. Furthermore, Flügge et al. (2018) found that the precision of intraoral scanners decreased as the distance between the scan bodies increased. However, the latest generation scanners may show minimal deviation values in complete arch impressions (Mangano et al., 2017).

\section{Powdering}

Dental tissues have many reflective surfaces, and this may cause some misfit in POI matching via by software. To eliminate this problem, the clinicians can alter the light diffusion by changing the orientation of the camera (Da Costa et al., 2010; Burgner et al., 2013; Joda and Brägger, 2016). Another solution to overcome this problem is the use of polarized filters within the camera systems. For other systems without polarized filter, the use of a titanium oxide powder, which has a thickness of 20-40 $\mu \mathrm{m}$, may be required. However, with the recent developing technology, most of the IOSs can overcome this problem and do not need to use a powder. Although, some researchers reported that powder based digital impressions showed very accurate results (Patzelt et al., 2014b; Richert et al., 2017), powder use may cause some comfort problems for patients and additional scanning time. Moreover, if the powder is contaminated with saliva during the scanning process, this require removing the powder from the teeth surface and re-scanning process. As a consequence, powder use is not comfortable during digital impressions and no clear difference can be found in the articles concerning the effect of powdering on scanning area.

\section{Artificial Intelligence (AI) in IOS}

It is commonly defined as "the ability of a system to interpret external data, learn from them, and use those learnings to achieve objectives and goals through flexible adaptation" (Lerner et al., 2020). IOS devices are frequently used in digital implantology, and one option is to use this technology in fabrication of customized abutments. Currently, these customized abutments can be designed in the CAD software and subsequently fabricated by subtractive (Milling) or additive manufacturing technologies (Direct Metal Laser Melting or Direct Metal Laser Sintering). In this workflow, dentists should acquire the true image of the scan body, which is screwed to the implant fixture, by the help of IOS devices; and subsequently, technician should carefully replace the .stl file of the scan body from the digital implant library files after importing the data to the CAD software (Lerner et al. 2020). With the help of AI technology, clinicians can mesh .stl file and digital library file during the scanning process by the help of data, which are previously imported to related software. This protocol allows the technicians to skip a lot of steps during the $3 \mathrm{D}$ design process. Also, this workflow can present a lot of guided points for complete arch scanning and may increase the accuracy of complete-arch digital implant impressions.

\section{Which optical impression optical system}

Although there are a lot of scientific studies, which focused on the accuracy of different optical systems, these research exhibit in vitro study results because it is impossible to measure the trueness values in in vivo studies. Some of these studies focused on dentate models and some of them evaluated the implant- supported restorations with different experimental designs. According to these studies, different devices with different technologies showed statistically different results. It is very difficult to compare the test results, as the scanners have different technologies and different scanning strategies (Park, 2016; Güth et al., 2017; Mangano et al., 2017). Scanning speed and scanning flow is a very important factor on selection criteria. The devices showed different scanning speeds, and the latest generation IOS devices showed faster results than the old version of IOS devices. Nevertheless, the literature cannot show which device is more efficient in terms of scanning speed (Mangano et al., 2017). The size of a tip also plays a major role as a selection criterion. Especially in case of second and third molars, the size of scanners tip becomes more important. A scanner with a tip of limited size would be preferable for patient comfort; however, bigger size tips may be useful for in posterior areas to acquire more data for per second. The detection of caries and acquiring 3D color models of dental arches are also new technologies, which are presented with the latest versions of IOS devices. The information on color become more meaningful especially in communication with patients. Also, some IOS devices can be used in shade determination; however, there isn't enough scientific literature, which compares the accuracy.

\section{Purchasing and cost}

Depending on the model, generation, and technology, the cost IOSs may differs between 15,000.00 and 35,000.00 euros. For 
ten years, companies have released a lot of technologies and features with the new generation models (Ting-Shu and Jian, 2015; Zimmermann et al., 2015; Imburgia et al., 2017). This growth in the supply is accompanied by the reduction in the purchase costs. Some companies have different policies, and they can request some managing cost and fee associated with software upgrades. It is important to inform the clinicians well about the additional managing cost (Mangano et al., 2017).

\section{Conclusion}

The future of dentistry is all about digital innovations and related technologies, and they will unquestionably develop the clinical practice with no doubt on this issue. Clinicians need to learn the new technologies and new workflows and also need to enhance their learning curve. An important step to enter this digital world is the use of IOS devices routinely and establishing private digital workflows. However, this rapid developing of technology makes the dentists have faced a new development and workflow every day. The main problem and the main question is not which one is better; the true question is when dentists will use the digital technology in every phase of their treatment workflow.

\section{References}

1. Burgner, J., Simpson, A., Fitzpatrick, J., Lathrop, R., Herrell, S., Miga, M., Webster Iii, R., 2013. A study on the theoretical and practical accuracy of conoscopic holography-based surface measurements: Toward image registration in minimally invasive surgery. Int. J. Med. Robot. 9, 190-203.

2. Chiu, A., Chen, Y.W., Hayashi, J., Sadr, A., 2020. Accuracy of $\mathrm{CAD} / \mathrm{CAM}$ digital impressions with different intraoral scanner parameters. Sensors. 20, 1157.

3. Da Costa, J., Pelogia, F., Hagedorn, B., Ferracane, J., 2010. Evaluation of different methods of optical impression making on the marginal gap of onlays created with CEREC 3D. Oper. Dent. 35, 324-329.

4. Ender, A., Mehl, A., 2013. Accuracy of complete-arch dental impressions: A new method of measuring trueness and precision. J. Prosthet. Dent. 109, 121-128.

5. Ender, A., Mehl, A., 2015. In-vitro evaluation of the accuracy of conventional and digital methods of obtaining full-arch dental impressions. Quintessence. Int. 46, 9-17.

6. Flügge, T., Van Der Meer, W.J., Gonzalez, B.G., Vach, K., Wismeijer, D., Wang, P., 2018. The accuracy of different dental impression techniques for implant-supported dental prostheses: A systematic review and meta-analysis. Clin. Oral. Implants. Res. 29, 374-392.

7. Geng, J., 2011. Structured-light 3D surface imaging: A tutorial. Adv. Opt. Photon. 3, 128-160.

8. Giachetti, L., Sarti, C., Cinelli, F., Russo, D.S., 2020. Accuracy of digital impressions in fixed prosthodontics: a systematic review of clinical studies. Int. J. Prosthodont. 33, 192-201.

9. Giménez, B., Özcan, M., Martínez-Rus, F., Pradíes, G., 2015. Accuracy of a digital impression system based on active wavefront sampling technology for implants considering operator experience, implant angulation, and depth. Clin. Implant. Dent. Relat. Res. 17, e54-e64.

10. Gjelvold, B., Chrcanovic, B.R., Korduner, E.K., Collin-Bagewitz, I., Kisch, J., 2016. Intraoral digital impression technique compared to conventional impression technique. A randomized clinical trial. J. Prosthodont. 25, 282-287.

11. Goracci, C., Franchi, L., Vichi, A., Ferrari, M., 2016. Accuracy, reliability, and efficiency of intraoral scanners for full-arch impressions: a systematic review of the clinical evidence. Eur. J. Orthod. 38, 422-428.

12. Grünheid, T., Mccarthy, S.D., Larson, B.E., 2014. Clinical use of a direct chairside oral scanner: an assessment of accuracy, time, and patient acceptance. Am. J. Orthod. Dentofacial. Orthop. 146, 673682.

13. Güth, J.F., Runkel, C., Beuer, F., Stimmelmayr, M., Edelhoff, D., Keul, C., 2017. Accuracy of five intraoral scanners compared to indirect digitalization. Clin. Oral. Investig. 21, 1445-1455.

14. Imburgia, M., Logozzo, S., Hauschild, U., Veronesi, G., Mangano, C., Mangano, F.G., 2017. Accuracy of four intraoral scanners in oral implantology: A comparative in vitro study. BMC. Oral. Health. 17, 92.

15. Ireland, A., Mcnamara, C., Clover, M., House, K., Wenger, N., Barbour, M., Alemzadeh, K., Zhang, L., Sandy, J., 2008. 3D surface imaging in dentistry-what we are looking at. Br. Dent. J. 205, 387-392.

16. Joda, T., Braegger, U., 2015. Time-efficiency analysis comparing digital and conventional workflows for implant crowns: a prospective clinical crossover trial. Int. J. Oral. Maxillofac. Implants. 30, 1047-1053.

17. Joda, T., Brägger, U., 2016. Patient-centered outcomes comparing digital and conventional implant impression procedures: A randomized crossover trial. Clin. Oral. Implants. Res. 27, e185e189.

18. Lee, S.J., Gallucci, G.O., 2013. Digital vs. conventional implant impressions: Efficiency outcomes. Clin. Oral. Implants. Res. 24, 111-115.

19. Lerner, H., Mouhyi, J., Admakin, O., Mangano, F., 2020. Artificial intelligence in fixed implant prosthodontics: a retrospective study of 106 implant-supported monolithic zirconia crowns inserted in the posterior jaws of 90 patients. BMC. Oral. Health. 20, 1-16.

20. Lim, J.H., Park, J.M., Kim, M., Heo, S.J., Myung, J.Y., 2018. Comparison of digital intraoral scanner reproducibility and image trueness considering repetitive experience. J. Prosthet. Dent. 119, 225-232.

21. Logozzo, S., Zanetti, E.M., Franceschini, G., Kilpelä, A., Mäkynen, A., 2014. Recent advances in dental optics Part I: 3D intraoral scanners for restorative dentistry. Opt. Laser. Eng. 54, 203-221.

22. Mangano, F., Gandolfi, A., Luongo, G., Logozzo, S., 2017. Intraoral scanners in dentistry: a review of the current literature. BMC. Oral. Health. 17, 149.

23. Mao, Z., Park, K., Lee, K., Li, X., 2014. Robust surface reconstruction of teeth from raw pointsets. Int. J. Numer. Method. Biomed. Eng. 30, 382-396.

24. Miyazaki, T., Hotta, Y., Kunii, J., Kuriyama, S., Tamaki, Y., 2009. A review of dental CAD/CAM: current status and future perspectives from 20 years of experience. Dent. Mater. J. 28, 4456.

25. Moörmann, W.H., 2006. The evolution of the CEREC system. J. Am. Dent. Assoc. 137, 7S-13S.

26. Müller, P., Ender, A., Joda, T., Katsoulis, J., 2016. Impact of digital intraoral scan strategies on the impression accuracy using the TRIOS Pod scanner. Quintessence. Int. 47, 343-349.

27. Park, J.M., 2016. Comparative analysis on reproducibility among 5 


\section{Ural and Kaleli / J Exp Clin Med}

intraoral scanners: sectional analysis according to restoration type and preparation outline form. J. Adv. Prosthodont. 8, 354-362.

28. Patzelt, S.B., Emmanouilidi, A., Stampf, S., Strub, J.R., Att, W., 2014a. Accuracy of full-arch scans using intraoral scanners. Clin. Oral. Investig. 18, 1687-1694.

29. Patzelt, S.B., Lamprinos, C., Stampf, S., Att, W., 2014b. The time efficiency of intraoral scanners: an in vitro comparative study. J. Am. Dent. Assoc. 145, 542-551.

30. Persson, A.S., Odén, A., Andersson, M., Sandborgh-Englund, G., 2009. Digitization of simulated clinical dental impressions: Virtual three-dimensional analysis of exactness. Dent. Mater. 25, 929-936.

31. Punj, A., Bompolaki, D., Garaicoa, J., 2017. Dental impression materials and techniques. Dent. Clin. North. Am. 61, 779-796.

32. Renne, W., Ludlow, M., Fryml, J., Schurch, Z., Mennito, A., Kessler, R., Lauer, A., 2017. Evaluation of the accuracy of 7 digital scanners: An in vitro analysis based on 3-dimensional comparisons.
J. Prosthet. Dent. 118, 36-42.

33. Richert, R., Goujat, A., Venet, L., Viguie, G., Viennot, S., Robinson, P., Farges, J.C., Fages, M., Ducret, M., 2017. Intraoral scanner technologies: A review to make a successful impression. J. Health. Eng. doi: 10.1155/2017/8427595.

34. Tamimi, F., Hirayama, H., 2019. Digital restorative dentistry. Springer International Publishing, Switzerland.

35. Taneva, E., Kusnoto, B., Evans, C.A., 2015. 3D scanning, imaging, and printing in orthodontics. Issues in Contemporary Orthodontics, Farif Bourzgui, eds. InTech, pp. 147-188.

36. Ting-Shu, S., Jian, S., 2015. Intraoral digital impression technique: A review. J. Prosthodont. 24, 313-321.

37. Zimmermann, M., Mehl, A., Mörmann, W., Reich, S., 2015. Intraoral scanning systems-a current overview. Int. J. Comput. Dent. 18, 101-129. 